\title{
Sudden cardiac death in children with congenital heart disease: a critical review of the literature
}

\section{Review Article}

Cite this article: Mishra V, Zaidi S, Axiaq A, and Harky A (2020) Sudden cardiac death in children with congenital heart disease: a critical review of the literature. Cardiology in the Young 30: 1559-1565. doi: 10.1017/

S1047951120003613

Received: 11 September 2020

Revised: 26 September 2020

Accepted: 2 October 2020

First published online: 28 October 2020

Keywords:

Arrest; heart; death; failure; anomaly

Author for correspondence:

A. Harky, MBChB, MRCS, MSc, Department of Cardiac Surgery, Alder Hey Children Hospital, Liverpool, UK. Tel: +44 151600 1616;

Fax: 0044-151-600-2774.

E-mail: aaharky@gmail.com

\section{Vaibhav Mishra ${ }^{1}$ (D), Sara Zaidi ${ }^{2}$, Ariana Axiaq $^{3}$ and Amer Harky ${ }^{4,5,6,7}$ (C)}

${ }^{1}$ School of Medicine, Faculty of Life Sciences, St George's, University of London, London, UK; ${ }^{2}$ School of Medicine, Faculty of Life Sciences, King's College London, London, UK; ${ }^{3}$ School of Medicine, Faculty of Life Sciences, Queen's University Belfast, Belfast, UK; ${ }^{4}$ Department of Cardiothoracic Surgery, Liverpool Heart and Chest, Liverpool, UK; ${ }^{5}$ Department of Integrative Biology, Faculty of Life Science, University of Liverpool, Liverpool, UK; ${ }^{6}$ Liverpool Centre for Cardiovascular Science, University of Liverpool and Liverpool Heart and Chest Hospital, Liverpool, UK and ${ }^{7}$ Department of Cardiac Surgery, Alder Hey Children Hospital, Liverpool, UK

\section{Abstract}

Sudden cardiac death is an uncommon but yet catastrophic event, which can occur in neonates and young children. Although extensive research has been carried out assessing the underlying causes, there still remains a degree of uncertainty around this area. Congenital heart disease (CHD) is one known cause of sudden cardiac death in children, the aetiology of which embraces virally induced mechanisms, genetic susceptibility, drug-induced, and maternal factors. Screening tools and investigations including electrocardiograms and echocardiograms alongside a concise history taking and physical examination can be used to identify the potential cardiovascular risk factors of sudden death. This review has comprehensively studied the causes and risk factors for sudden cardiac death in children with CHD and provides a collation and summary of the evidence available so far underpinning the complex link between the two. Moreover, current screening and prevention methods are discussed in detail in order to increase awareness and understanding of how we can improve patient outcomes.

CHD is one of the most common birth defects in newborn babies. ${ }^{1}$ Although extremely rare, these malformations can lead to sudden cardiac death during early childhood. Sudden cardiac death is a tragic and calamitous event defined as natural death, which is cardiovascular in nature and illustrated through an abrupt loss of consciousness within an hour of the onset of cardiac symptoms. $^{2}$ The annual paediatric incidence rate of sudden cardiac death can vary depending on age-specific groups but overall, it is estimated to be around 1.7 per 100,000 population and 7.5 per 100,000 children. ${ }^{3}$ It is suspected that $5-10 \%$ of sudden cardiac death in these patients is due to CHD and genetically determined primary electrical disturbances. ${ }^{2}$ The intention of this review is to comprehensively study this interrelation and determine which interventions are efficacious in reducing the incidence of childhood sudden cardiac death in patients with CHD.

\section{Aetiology}

There can be multiple causes associated with sudden cardiac death in the paediatric population (Fig 1$)^{4}$ and even more underlying causes for the development of CHDs. The asymptomatic nature of many CHDs can contribute to children not being screened appropriately or having relevant cardiac examinations, and often this results in late discovery of the underlying pathology at autopsy.

\section{Virally induced mechanisms}

CHDs can be linked to external risk factors including foetal exposure to retinoic acid as well as viral infections in the mother. Some studies suggest that maternal infection with rubella and cytomegalovirus poses an increased risk the development CHD in the foetus. A recent metaanalysis of observational studies of 67,233 women, showed that mothers who suffered from viral infections in their first trimester of pregnancy resulted in a higher global risk of their offspring developing CHD (odds ratio [OR], 1.83; 95\% CI, 1.58-2.12; $\mathrm{p}<0.0001$ ). Specifically, the risk of CHD development was greatly increased in cases where mothers had been infected with the rubella virus (OR, 3.49, 95\% CI, 2.39-5.11) and cytomegalovirus (OR, 3.95; 95\% CI, 1.87-8.36). ${ }^{5}$ Similarly, another meta-analysis of case-control studies, studying 524 children with CHD against 262 controls, demonstrated that maternal upper respiratory tract infection (influenza virus) in early pregnancy was associated with an increased risk of their offspring developing CHD (OR 3.40; 95\% CI: 2.05-5.62 for simple CHD cases and OR 2.39; 95\% CI: 1.47-3.88 for complex CHD cases). After a meta-analysis, the adverse impact was still kept 

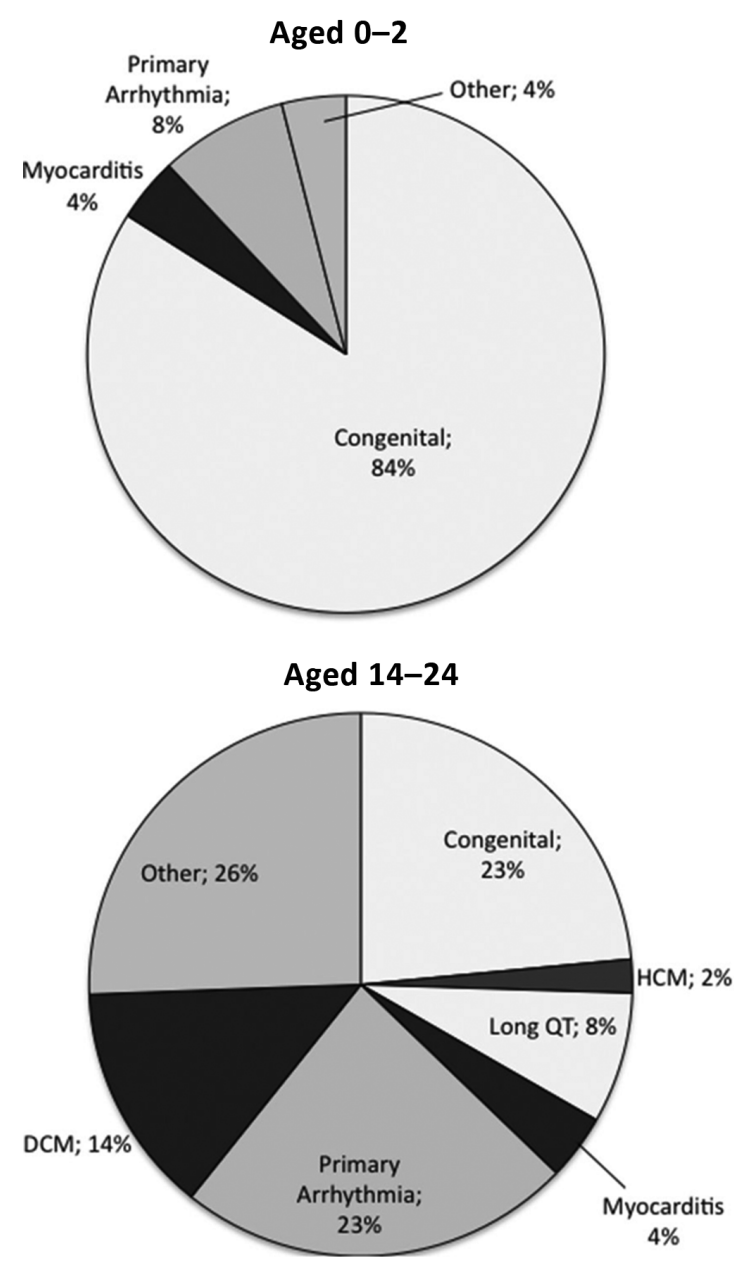

Figure 1. Aetiology of SCD by age group. ${ }^{4}$

significant $(\mathrm{OR}=1.47$ and $95 \% \mathrm{CI}$ : $1.28-1.67$ for simple $\mathrm{CHD}$; $\mathrm{OR}=1.44$ and $95 \% \mathrm{CI}: 1.14-1.75$ for complex CHD), same findings were also seen with ventricular septal defects. ${ }^{6}$

\section{The genetic interplay}

Another notable cause of CHD development is genetic factors, specifically some aneuploidies and gene mutations. Trisomy 21 (Down's syndrome) is the commonest chromosomal abnormality associated with $\mathrm{CHD}^{7}$ with the commonest $\mathrm{CHD}$ being an atrioventricular septal defect, ventricular septal defect, atrial septal defect, patent ductus arteriosus, and Tetralogy of Fallot. ${ }^{8}$ Results from a matched cohort Australian study indicated a higher incidence of cardiovascular endpoints in Down's syndrome patients than those without Down's syndrome. Not only was the prevalence of CHD higher in the Down's syndrome cohort, but also the incidence of coronary events such as myocardial infarction was higher. ${ }^{9}$ Likewise, another study looking into 93 Down's syndrome patients found a $16.3 \%$ mortality at a mean age of 19 months of age. ${ }^{10}$ Despite the small sample size, it is clear that Down's syndrome patients experience higher mortality rates due to underlying CHDs. The second genetic cause of CHD is Turner's syndrome, affecting females, with the karyotype $(45, \mathrm{XO})$. Occurring in $\approx 1$ in 2500 live female births, ${ }^{11}$ common cardiac defects associated here commonly include bicuspid aortic valve and coarctation of the aorta. These, along with systemic hypertension, can lead to
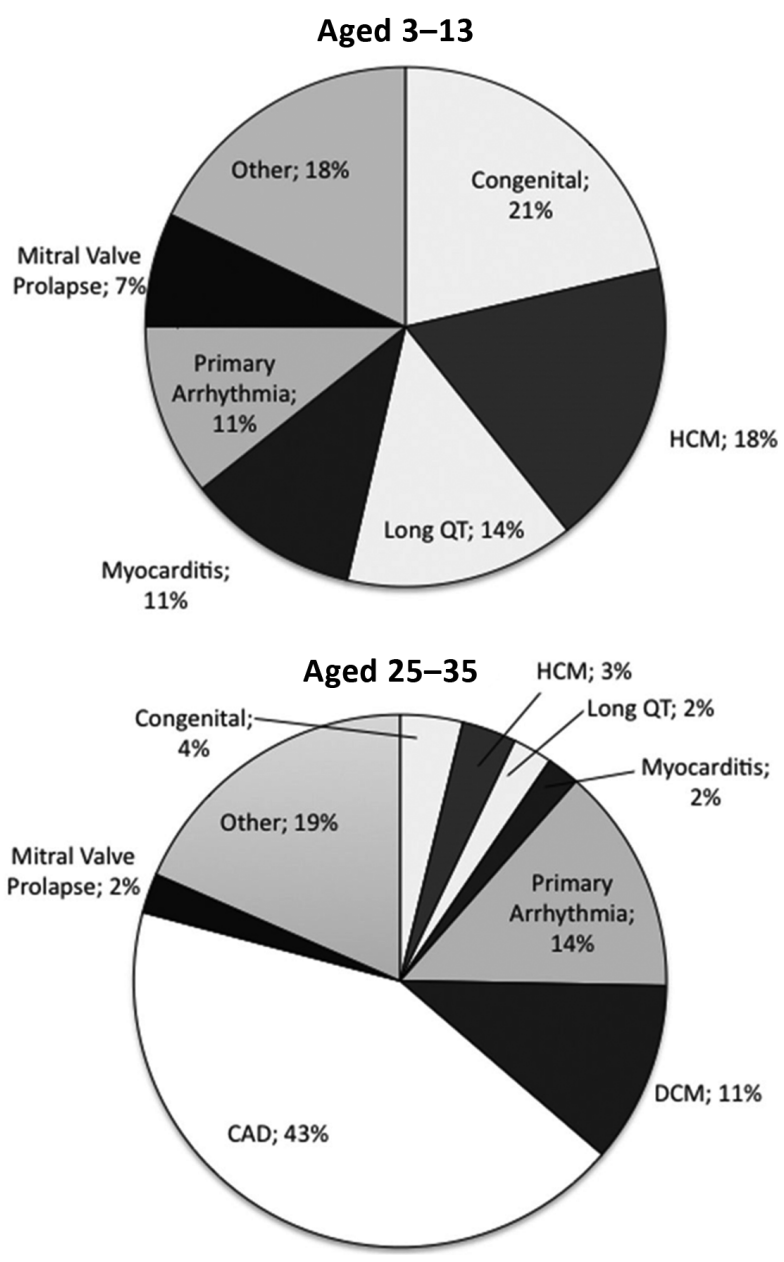

aortic dilatation and dissection, ${ }^{12}$ hence increasing the risk of sudden cardiac death. This also emphasises the requirement for screening echocardiogram upon diagnosing patients with Turner's syndrome to assess their cardiac health, identify potential pathology, and arrange early intervention if needed. Noonan's syndrome, an autosomal dominant condition, also presents with CHD. Caused by missense mutations in the PTPN11 gene, which encodes for the phosphatase SHP2, it results in increased activation of the RAS/extracellular signal-regulated kinase (ERK)/mitogenactivated protein kinase (MAPK) pathway. Common CHDs in patients with Noonan's syndrome include pulmonary valve stenosis, atrial septal defects, and congenital hypertrophic cardiomyopathy and mitral valve defects. ${ }^{13}$ Sudden cardiac death is a concern in patients with Noonan's syndrome, particularly due to congenital hypertrophic cardiomyopathy being a major risk factor; for example, Ramond et al in 2017 reported a fatal case of a patient with Noonan's syndrome, who had a sudden cardiac death event whilst running. ${ }^{14}$

\section{Diabetes and CHD}

Furthermore, another risk factor that is linked with foetal development of CHD is maternal diabetes mellitus. In particular, hyperglycaemia is thought to be the primary teratogen. ${ }^{15}$ The time period in which the mother develops diabetes can have different effects on foetal development. ${ }^{16}$ Whilst developing diabetes 
mellitus prior to conception may lead to neural tube, vasculature, and cardiac defects, ${ }^{17}$ developing gestational diabetes mellitus later on in the gestational period may lead to congenital cardiomyopathy. ${ }^{18}$ To supplement this, a population-based study on 1583 babies of mothers with type 1 diabetes mellitus, demonstrated an increased prevalence of CHD-born babies to mothers with type 1 diabetes mellitus against the background population $(\mathrm{OR}=3.5$; CI: $2.7-4.7){ }^{19}$

\section{Drugs and their teratogenic properties}

Many drugs are contraindicated in pregnancy due to their adverse foetal outcomes. Maternal lithium use, for the treatment of bipolar disorder, has been shown to increase the risk of foetal right ventricular outflow tract obstructions. ${ }^{20}$ Ebstein's anomaly, in particular, is a congenital defect of the tricuspid valve and associated with the use of lithium during pregnancy. ${ }^{20}$ The poor outcomes linked with Ebstein's anomaly have been well documented since the 90s. One study assessed the presentation and outcomes of 50 children with Ebstein's anomaly. ${ }^{21} 18 \%$ died in the neonatal period, $30 \%$ died at a mean age of 4.5 years due to haemodynamic deterioration, and $10 \%$ of the patients died suddenly at various different ages. Use of angiotensin-converting enzyme inhibitors during the first trimester has also been reported to have adverse fetal cardiovascular outcomes. A study by Cooper et al analysed a cohort of 29,507 infants of whom there were 209 infants who had been exposed to angiotensin-converting enzyme inhibitors in the first trimester and 202 infants who had been exposed to other anti-hypertensives. Infants exposed to angiotensin-converting enzyme inhibitors were at increased risks of malformations involving the cardiovascular and central nervous systems when compared to infants who had exposure to other antihypertensives or no drug exposure at all. ${ }^{22}$ Veroniki et al also identified that the use of certain anti-epileptic drugs during pregnancy increased the risk of cardiac malformations. The drug combinations which were identified included gabapentin monotherapy, carbamazepine plus phenytoin, phenobarbital plus sodium valproate, phenytoin plus sodium valproate, and carbamazepine plus clonazepam. However, newer generation anti-epileptics drugs such as levetiracetam and lamotrigine were deemed safer. ${ }^{23}$

\section{Maternal factors}

Maternal cigarette smoking during pregnancy is a significant risk factor for CHDs and may account for $1.4 \%$ of all CHDs. ${ }^{24}$ A population-based study by Sullivan et al explored the relation between CHDs and smoking during the first trimester and found that offspring of smoking mothers were at increased risk of CHD, especially pulmonary valve anomalies, pulmonary artery anomalies, and atrial septal defects. ${ }^{24}$ Another interesting risk factor for the development of CHDs is the use of assisted reproductive technology such as in vitro fertilisation and intracytoplasmic sperm injection. A study in the USA analysed this association and found that conception by assisted reproductive technology had a greater risk of birth defects when compared to spontaneous conception. More importantly, the birth defects most commonly associated were cyanotic heart defects, with a frequency of $0.50 \%$ in the assisted reproductive technology group and $0.07 \%$ in the spontaneous pregnancy group. ${ }^{25}$ This is supported by another study by Shamshirsaz et al who also discovered that fertility treatments led to increased risks in the development of foetal cyanotic heart defects. ${ }^{26}$ It is thought that along with the process of the treatment itself, the parental subfertile substrate may also be an underlying mechanism, and hence the use of
Table 1. A summary of the congenital cardiovascular defects affecting the paediatric population

\begin{tabular}{|c|c|}
\hline \multicolumn{2}{|l|}{$\begin{array}{l}\text { Congenital cardiac } \\
\text { defects }\end{array}$} \\
\hline $\begin{array}{l}\text { Structural heart } \\
\text { defects }\end{array}$ & $\begin{array}{l}\text { Simple: } \\
\text { - Ventricular septal defect } \\
\text { - Atrial septal defect } \\
\text { - Valvular stenosis } \\
\text { - Coarctation of the aorta } \\
\text { - Patent ductus arteriosus } \\
\text { Complex: } \\
\text { - Atrioventricular septal defect } \\
\text { - Hypoplastic left heart syndrome } \\
\text { - Tetralogy of Fallot } \\
\text { - Transposition of the great arteries } \\
\text { - Pulmonary atresia }\end{array}$ \\
\hline $\begin{array}{l}\text { Primary electrical } \\
\text { disturbances }\end{array}$ & $\begin{array}{l}\text { - Long QT syndrome } \\
\text { - Brugada syndrome } \\
\text { - Catecholaminergic polymorphic ventricular } \\
\text { tachycardia }\end{array}$ \\
\hline $\begin{array}{l}\text { Congenital coronary } \\
\text { artery anomalies }\end{array}$ & $\begin{array}{l}\text { - Anomalous origin of the left coronary artery } \\
\text { from the right sinus of Valsalva } \\
\text { - Anomalous origin of the right coronary artery } \\
\text { from the left sinus of Valsalva } \\
\text { - Single coronary artery }\end{array}$ \\
\hline
\end{tabular}

assisted reproductive technology warrants screening via fetal echocardiography. ${ }^{26}$

\section{Classification}

Congenital abnormalities which lead to sudden cardiac death in children can be classified into congenital structural heart defects, congenital coronary artery anomalies, and congenital cardiac arrhythmias, otherwise known as primary electrical disturbances. ${ }^{27}$ Table 1 lists the conditions which fall into each category with congenital structural heart defects further subdivided into simple and complex defects. ${ }^{28}$

It is important to differentiate between simple and complex structural heart defects as sudden cardiac death in children aged $<1$ year is more frequently associated with the latter. ${ }^{28}$ One retrospective study identified 64 cases of children with CHDs presenting with sudden death with half of these cases undiagnosed preceding autopsy. $81 \%$ of this cohort was infants and the commonest malformation was found to be atrioventricular septal defects, a complex defect. ${ }^{28}$ Complex cardiac congenital defects progressing to sudden cardiac death is further supported in a review by Liberthson which identified literature in which patients with Tetralogy of Fallot had a 6\% risk of sudden cardiac death, between 3 months and 20 years of age, after reparative surgery and individuals following an atrial switch operation for transposition of the great arteries were associated with a $2-8 \%$ risk of sudden cardiac death. ${ }^{28,29}$ Although these findings do not identify the risks associated exclusively with children $<18$ years, it is still noteworthy as the combination of these findings highlight that the fatal consequences of CHD still linger even after corrective interventions. This places emphasis on the importance of continued perusal in this area of study.

Complex CHDs also tend to coexist with congenital coronary artery anomalies. ${ }^{30}$ Although most cases of congenital coronary artery anomalies tend to be benign, in isolation, congenital coronary artery anomalies can be associated with myocardial ischaemia, 
ventricular arrhythmias, and sudden death. ${ }^{31}$ Anomalous aortic origin of the left coronary artery from the right sinus of Valsalva accounts for roughly $40 \%$ of all major coronary anomalies, however, is deemed to have little clinical significance. Anomalous aortic origin of the right coronary artery from the left sinus of Valsalva is estimated to account for $35 \%$ of major coronary anomalies and is important in that it can lead to myocardial ischaemia and sudden cardiac death. Another variant is when there is a single coronary artery and half of the cases are usually encountered alongside other forms of CHD. ${ }^{32}$ Variants with coronary arteries which follow an interarterial course between the aorta and pulmonary artery are thought to have the highest risks of sudden cardiac death, especially when the young individual is engaging with strenuous physical exertion. ${ }^{33}$ One study analysed clinical and pathological reports in 242 patients with isolated congenital coronary artery anomalies to identify the frequency and mechanisms pinned with sudden cardiac death. ${ }^{34} \mathrm{~A}$ key finding was that the younger patients ( $<30$ years old) were at a greater risk of sudden cardiac death, especially following exercise or significant exertion. Although this included patients beyond the paediatric population, it warrants further probing to determine which age groups are most at risk.

\section{Neonates and infants}

Congenital malformations are the chief cause of neonatal death, occurring in $2-3 \%$ of live births. Structural heart disease is diagnosed in the first year of life in $4-8 / 1000$ infants and $10 \%$ of these cases have fatal consequences. The predominant diagnoses made in neonates include hypoplastic left heart syndrome, pulmonary atresia and transposition of the great arteries, all of which are severe and can lead to cyanosis, congestive heart failure, cardiovascular collapse, and shock. ${ }^{35}$ In addition, aortic valve stenosis, coarctation of the aorta, and Tetralogy of Fallot are also severe diagnoses, which may be recognised in the first year of life. Sudden unexpected neonatal death and sudden infant death syndrome are both phenomena, which share certain features and have also been shown to have underlying cardiac causes. ${ }^{36,37}$ A retrospective analysis by Weber et al found that out of 32 explained sudden unexpected neonatal death associated with undiagnosed congenital abnormalities, 12 (38\%) were attributable to clinically undetected structural CHD including transposition of the great arteries, coarctation of the aorta, hypoplastic left heart syndrome, and pulmonary atresia. Thus, $\mathrm{CHD}$ was the commonest single group of congenital malformations associated with sudden unexpected neonatal death. ${ }^{36}$ Although this is a significant value when discussed alongside the sample size and should be included when assessing the burden of sudden cardiac death in paediatric CHD patients, it is believed that sudden cardiac death is more likely to occur in patients beyond the neonatal period and a third of CHD deaths occur during infancy.

Sudden infant death syndrome is most commonly related to environmental factors such as sleeping positions, sleeping environment, and smoking during pregnancy. However, cardiac disorders and especially congenital arrhythmias are responsible for a small number of cases. ${ }^{37}$ Congenital arrhythmias encompass a spectrum of different electrical disturbances including Brugada syndrome, long QT syndrome, and catecholaminergic polymorphic ventricular tachycardia, amongst others. In particular, the long QT syndrome has been suggested to have strong associations with sudden cardiac death in early childhood. ${ }^{38}$ It is commonly known to progress towards torsades de pointes, ventricular tachycardia and fibrillation manifesting as seizures and syncope in seemingly healthy individuals, and so it is understandable as to why this link has been speculated in the past. One genetic study by Arnestad et al demonstrated that $9.5 \%$ of patients who suffered from sudden infant death syndrome were found to carry functionally significant variants of long QT syndrome genes, which may have contributed to this premature death. However, without electrocardiogram evidence prior to death, it is difficult to conclude a definite relation between long QT syndrome and sudden infant death syndrome. ${ }^{39}$ Another genetic analysis in Korea also identified a number of sudden infant death syndrome victims $(7.5 \%)$ who carried gene variants associated with long QT syndrome, but then found that this variation may also be a common polymorphism in Asians and hence failed to demonstrate a favourable link between long QT syndrome and sudden infant death syndrome. ${ }^{40}$ A key limitation of both of these studies is that DNA investigations use anonymised data to draw conclusions, and hence, this prevents identification and provision of prophylactic therapy to relatives of the deceased individuals who may also be mutation carriers and at increased risk of sudden cardiac death. However, if the overall results fail to show any meaningful relation between long QT syndrome and sudden infant death syndrome then prophylaxis, in any case, may not be beneficial. The results from both of these studies show that whilst some genetic links have been identified, further objective assessments and studies are needed in order to support previous claims of sudden death during childhood in patients with long QT syndrome. ${ }^{38}$

\section{Screening and prevention}

A crucial element in improving mortality rates from sudden cardiac death is prevention. In such cases, earlier the patient is diagnosed and treated, the better survival chances. However, apart from primary prevention, secondary prevention strategies have been implemented with the aim of deterring further cardiac damage. Screening is the first step forward. With sudden cardiac death occurring in young individuals in seemingly good health, screening for potential risk factors is essential, particularly when these individuals lead an athletic lifestyle. ${ }^{41}$ Exercise exacerbates the effects of CHD, however, $73 \%$ of sudden cardiac arrest has been reported to occur when the patient is sedentary. ${ }^{42}$ In a study by Mahoney et al 1996, 13\% of individuals with sudden cardiac arrest between 2 and 24 years were found to have at least one cardiovascular risk factor. ${ }^{43}$ For this reason, dietary and safe exercise has been publicly recommended. Genetic analysis of sudden cardiac arrest in patients can still be beneficial for relatives. Cascade testing is an important screening mechanism to identify causative mutations, considering a likelihood of $25-50 \%$ of firstdegree relatives experiencing sudden cardiac arrest in their lifetime. In a retrospective study at a tertiary paediatric referral centre, following evaluation of paediatric patients with a family history of sudden death, 9.3\% were diagnosed with a hereditary cardiac disease with $\mathrm{Q} \mathrm{T}$ syndrome being the most common diagnosis. In $5.5 \%$ of all patients, non-hereditary cardiac disease diagnosis had been made and in another $12.4 \%$, findings of uncertain significance resulted. ${ }^{44}$

For selecting patients with likely sudden cardiac arrest, algorithms should be developed pivoting around symptoms and their manifestation in clinical events. The risk of sudden cardiac arrest in individuals with a history of aborted or resuscitated sudden cardiac arrest is high, other symptoms that may aim in diagnosis include palpitations, chest pain, syncope, and seizures all generally linked to non-sustained arrhythmia. Between 25 and 50\% of children 
with sudden cardiac arrest have experienced previous symptoms, normally syncope and seizure. ${ }^{45}$ Notwithstanding, apart from syncope, such antecedent symptoms are very common in children and adolescents introducing imprecision in prediction. Additionally, screening strategies have been suggested by the National Heart Lung and Blood Institute. Due to cost-benefit reasons, cardiovascular screening should focus on high-risk groups, such as athletes since asymptomatic screening of young individuals has proved to be ineffective. A multitude of assessment methods have been suggested with ECG, physical examination, and history taking as the best contenders. ${ }^{46}$ Whilst algorithms may enhance the efficiency of ECG delivery, the precision and accuracy of these tests are dependent on population prevalence, age, and medication in use. Risk stratification for paediatric patients may also be limited to specific disease criteria, for example, diagnosis of hypertrophic cardiomyopathy and channelopathies. However, being based on adult guidelines, their validity for paediatric population may be contested. ${ }^{47}$

Following identification of high-risk individuals, suitable precautionary measures should be taken. An example of this is implantable cardioverter-defibrillator implantation. Findings on the application for implantable cardioverter-defibrillator in paediatric patients are conflicting. Evidence on their use for primary prophylaxis in children is less substantial than in adult counterparts. The risk in implantation of implantable cardioverterdefibrillator is, however, higher in paediatric patients due to lead malfunctions, shock frequency, and difficulty experienced in implantation resulting from the small size of patients and intracranial structures. ${ }^{48}$

Another key feature of secondary prevention is cardiopulmonary resuscitation and automated external defibrillators. In an American study, emergency medical service staff were trained to make a preliminary assessment of the cause of sudden cardiac arrest before initiating a cause-specific cardiopulmonary resuscitation. This resulted in better outcomes than in cases when the sudden cardiac arrest cause was not identified to be cardiac or non-cardiac. However, due to time limitations, the extent of pre-cardiopulmonary resuscitation assessment may be restricted. ${ }^{49}$ Cardiopulmonary resuscitation training programmes for family members and teachers of paediatric patients with $\mathrm{CHD}^{50}$ together with the provision of self-instruction kits is another facet of secondary prevention aimed at increasing the survival rate from sudden cardiac arrest. ${ }^{51}$ Nonetheless, results from a multicentre study suggest that cardiopulmonary resuscitation alone is not as effective as cardiopulmonary resuscitation in conjunction with automated external defibrillators availability. With out-of-hospital cardiac arrest outcomes being low and survival rate being reduced by $10 \%$ for each minute cardiopulmonary resuscitation is delayed, ${ }^{52}$ cardiopulmonary resuscitation-automated external defibrillators programmes have become increasingly popular in community settings. This stems from the fact that some individuals may have not been identified via screening and cardiac arrest is the first presentation of their underlying heart disease. ${ }^{53}$ Such programmes have been recommended through guidelines by the American Heart Association, indicating that schools with high-risk individuals for sudden cardiac arrest such as patients of cardiomyopathies, channelopathies, congenital, or known cardiovascular disease would require the onsite presence of automated external defibrillators machines. ${ }^{54} \mathrm{With}$ automated external defibrillators still being inaccessible to some areas, wearable off-brand automated external defibrillators might also provide a solution. ${ }^{55}$

\section{Discussion}

Overall, this review has canvassed a number of causes of CHD encompassing viral, genetic, endocrinological, drug related, and maternal. The prevalence of these aetiologies has been discussed and studies of statistical significance have been pulled apart to closely analyse the increased risk of developing CHDs in these individuals. With regards to viral aetiology, maternal infection with rubella and the influenza virus were the most closely related to CHD. The meta-analyses which highlighted these results showed no publication bias and hence this is indicative of influential credibility. The large sample sizes selected in these studies further display a lack of bias. Furthermore, we were able to identify which genetic conditions had the highest risk of cardiovascular complications. Down's syndrome, Turner's syndrome, and Noonan's syndrome are widely known to have severe cardiac manifestations and unfortunately in these patients, sudden death can occur during childhood owing to severe instabilities of the circulatory system. We reviewed case reports of children to identify those with genetic disorders suffering from sudden cardiac death, and these were based on individual cases or a few patients at a time and therefore, unfortunately, our conclusions cannot be generalised to include different epidemiological populations. There are a vast number of causes for CHD which exist in different proportions according to geographic locations and so patient demographics are a significant varying factor. The most important drugs identified which were shown to be directly linked to birth defects, especially cardiovascular, were lithium, angiotensin-converting enzyme inhibitors, and a number of anti-epileptic drugs.

$\mathrm{CHD}$ and structural heart disease form one part of a spectrum of congenital cardiac disorders, which predispose an individual to sudden cardiac death, and so we found that further classification of disease types based on anatomy and physiology aids in the understanding of the specific mechanisms underlying premature death. As a result, we were able to include our assessment of not only structural heart defects, but also congenital coronary artery anomalies and primary electrical disturbances. This review found that those CHDs considered being complex in both pathophysiology and management were more likely to lead to sudden cardiac death. The small sample sizes discussed, however, may negatively impact our deductions and this mandates further studies analysing these conclusions. Complex CHDs sometimes also appear alongside congenital coronary artery anomalies and these in isolation increase the risk of sudden cardiac death, therefore, it can be hypothesised that the combination of both can have dire consequences. Having reviewed the literature available, it is our opinion that there is insufficient research exposing the links between sudden unexpected neonatal death and sudden infant death syndrome with CHD, and therefore this link should have an important role in future research. Long QT syndrome has been hypothesised to have a role in sudden cardiac death in children $<1$ year. We managed to explore this through genetic studies; however, both demonstrated a weak or insignificant relationship. Electrocardiogram evidence of pathology would be useful to document in future studies in order to uncover the exact nature and causes of death.

A key part of our aim was to highlight strategies, which could reduce mortality rates in children with $\mathrm{CHD}$. Our thorough analysis of the primary and secondary prevention strategies, which have been implemented so far has allowed us to understand the pivotal role of screening in those with cardiovascular risk factors and the importance of widespread cardiopulmonary resuscitation training and availability of automated external defibrillators. Implantable 
cardioverter-defibrillator implantation in those children at risk is debatable and this is a decision, which should be made on a caseby-case basis through the involvement of senior clinicians and via a multidisciplinary approach. The literature reviewed has allowed us to appreciate that defibrillation outcome for children and adolescents with sudden cardiac arrest is poorer than that in adults. The discrepancy for this is still elusive. Moreover, the safety of automated external defibrillators for infants younger than 1 year has not been safely established. Instead of direct application of knowledge about adults with CHD, more research about the suitability of screening as well as implantable cardioverter-defibrillator implantation should be conducted specifically targeted towards a paediatric population.

\section{Conclusion}

The high incidence of sudden cardiac death in paediatric populations, in particular in younger patients has made it a pressing issue for clinicians and whilst a plethora of factors may contribute to sudden cardiac death, CHD is a known precursor. Successful classification along with continued surveillance of the type of CHD displayed may be a crucial determinant in ameliorating survival of patients. With primary and secondary prevention strategies studies underway, more emphasis is required on the difference between adult and paediatric patients. This review attempted to discuss both established frameworks in sudden cardiac death related to CHD as well as identify potential areas of study. For this reason, a more proactive approach should be encouraged in studying the effectiveness of existent measures and for a more profound understanding of the association between sudden cardiac death and CHD.

\section{Acknowledgements. None.}

Financial support. This research received no specific grant from any funding agency, commercial, or not-for-profit sectors.

Conflicts of interest. None.

\section{References}

1. Lowry RB. Common congenital anomalies. Can Fam Physician 1985; 31: 1033-1037.

2. Zeigler VL, Payne L. Sudden cardiac death in the young. Crit Care Nurs $Q$ 2010; 33: 219-232. doi: 10.1097/CNQ.0b013e3181e65f98

3. Chugh SS, Reinier K, Balaji S, et al. Population-based analysis of sudden death in children: the Oregon sudden unexpected death study. Heart Rhythm 2009; 6: 1618-1622. doi: 10.1016/j.hrthm.2009.07.046

4. Meyer L, Stubbs B, Fahrenbruch C, et al. Incidence, causes, and survival trends from cardiovascular-related sudden cardiac arrest in children and young adults 0 to 35 years of age: a 30-year review. Circulation 2012; 126: 1363-1372. doi: 10.1161/CIRCULATIONAHA.111.076810

5. Ye Z, Wang L, Yang T, et al. Maternal viral infection and risk of fetal congenital heart diseases: a meta-analysis of observational studies. J Am Heart Assoc 2019; 8. doi: 10.1161/JAHA.118.011264

6. Xia YQ, Zhao KN, Zhao AD, et al. Associations of maternal upper respiratory tract infection/influenza during early pregnancy with congenital heart disease in offspring: evidence from a case-control study and metaanalysis. BMC Cardiovasc Disord 2019; 19: 277. doi: 10.1186/s12872019-1206-0

7. Hartman R, Rasmussen S, Botto L, et al. The contribution of chromosomal abnormalities to congenital heart defects: a population-based study. Pediatr Cardiol 2011; 32: 1147-1157.
8. Allen HD, Driscoll DJ, Shaddy RE, Feltes TF. Moss and Adams' Heart Disease in Infants, Children, and Adolescents: Including the Fetus and Young Adult, 8th edn. Wolters Kluwer Health/Lippincott Williams \& Wilkins, Philadelphia, PA, 2013.

9. Sobey C, Judkins C, Sundararajan V, Phan T, Drummond G, Srikanth V. Risk of major cardiovascular events in people with down syndrome. PLOS ONE 2015; 10: e0137093.

10. Abbag FI. Congenital heart diseases and other major anomalies in patients with down syndrome. Saudi Med J 2006; 27: 219-222.

11. Nielsen J, Wohlert M. Chromosome abnormalities found among 34,910 newborn children: results from a 13-year incidence study in Arhus, Denmark. Hum Genet 1991; 87: 81-83.

12. Sybert VP. Cardiovascular malformations and complications in Turner syndrome. Pediatrics 1998; 101: E11. doi: 10.1542/peds.101.1.e11

13. Pierpont M, Brueckner M, Chung W, et al. Genetic basis for congenital heart disease: revisited: a scientific statement from the American Heart Association. Circulation 2018; 138: e653-e711.

14. Ramond F, Duband S, Croisille P, et al. Expanding the cardiac spectrum of Noonan syndrome with RIT1 variant: left main coronary artery atresia causing sudden death. Eur J Med Genet 2017; 60: 299-302.

15. Negrato C, Mattar R, Gomes M. Adverse pregnancy outcomes in women with diabetes. Diabetol Metab Syndr 2012; 4: 41.

16. Basu M, Garg V. Maternal hyperglycemia and fetal cardiac development: clinical impact and underlying mechanisms. Birth Defects Res 2018; 110: 1504-1516.

17. Zhao Z, Reece EA. New concepts in diabetic embryopathy. Clin Lab Med 2013; 33: 207-233.

18. Kc K, Shakya S, Zhang H. Gestational diabetes mellitus and macrosomia: a literature review. Ann Nutr Metab 2015; 66 (Suppl 2): 14-20.

19. Eidem I, Stene L, Henriksen T, et al. Congenital anomalies in newborns of women with type 1 diabetes: nationwide population-based study in Norway, 1999-2004. Acta Obstet Gynecol Scand 2010; 89: 1403-1411.

20. Patorno E, Huybrechts KF, Bateman BT, et al. Lithium use in pregnancy and the risk of cardiac malformations. N Engl J Med 2017; 376: 2245-2254. doi: 10.1056/NEJMoa1612222

21. Celermajer DS, Cullen S, Sullivan ID, Spiegelhalter DJ, Wyse RK, Deanfield JE. Outcome in neonates with Ebstein's anomaly. J Am Coll Cardiol 1992; 19: 1041-1046. doi: 10.1016/0735-1097(92)90291-t

22. Cooper WO, Hernandez-Diaz S, Arbogast PG, et al. Major congenital malformations after first-trimester exposure to ACE inhibitors. N Engl J Med 2006; 354: 2443-2451. doi: 10.1056/NEJMoa055202

23. Veroniki AA, Cogo E, Rios P, et al. Comparative safety of anti-epileptic drugs during pregnancy: a systematic review and network meta-analysis of congenital malformations and prenatal outcomes. BMC Med 2017; 15: 95. doi: 10.1186/s12916-017-0845-1

24. Sullivan PM, Dervan LA, Reiger S, Buddhe S, Schwartz SM. Risk of congenital heart defects in the offspring of smoking mothers: a population-based study. J Pediatr 2015; 166: 978-984.e2. doi: 10.1016/j.jpeds.2014.11.042

25. Shechter-Maor G, Czuzoj-Shulman N, Spence AR, Abenhaim HA. The effect of assisted reproductive technology on the incidence of birth defects among livebirths. Arch Gynecol Obstet 2018; 297: 1397-1403. doi: 10.1007/ s00404-018-4694-8

26. Shamshirsaz AA, Bateni ZH, Sangi-Haghpeykar H, et al. Cyanotic congenital heart disease following fertility treatments in the United States from 2011 to 2014. Heart 2018; 104: 945-948. doi: 10.1136/ heartjnl-2017-312015

27. Wren C. Sudden death in children and adolescents. Heart 2002; 88: 426-431. doi: 10.1136/heart.88.4.426

28. Serinelli S, Arunkumar P, White S. Undiagnosed congenital heart defects as a cause of sudden, unexpected death in children. J Forensic Sci 2018; 63: 1750-1755. doi: 10.1111/1556-4029.13779

29. Liberthson RR. Sudden death from cardiac causes in children and young adults. N Engl J Med 1996; 334: 1039-1044. doi: 10.1056/NEJM19960 4183341607

30. Lowry AW, Olabiyi OO, Adachi I, Moodie DS, Knudson JD. Coronary artery anatomy in congenital heart disease. Congenit Heart Dis 2013; 8: 187-202. doi: 10.1111/chd.12067 
31. Frommelt PC. Congenital coronary artery abnormalities predisposing to sudden cardiac death. Pacing Clin Electrophysiol 2009; 32 (Suppl 2): S63-S66. doi: 10.1111/j.1540-8159.2009.02387.x

32. Flores S, Moore RA, Statile CJ, et al. Critical care for patients with congenital abnormalities of the coronary arteries. Cardiol Young 2015; 25: 1561-1566. doi: 10.1017/S104795111500205X

33. Brothers JA. Coronary artery anomalies in children: what is the risk? Curr Opin Pediatr 2016; 28: 590-596. doi: 10.1097/MOP.00000000000 00399

34. Taylor AJ, Rogan KM, Virmani R. Sudden cardiac death associated with isolated congenital coronary artery anomalies. J Am Coll Cardiol 1992; 20: 640-647. doi: 10.1016/0735-1097(92)90019-j

35. Pinar H. Postmortem findings in term neonates. Semin Neonatol 2004; 9: 289-302. doi: 10.1016/j.siny.2003.11.003

36. Weber MA, Ashworth MT, Risdon RA, Brooke I, Malone M, Sebire NJ. Sudden unexpected neonatal death in the first week of life: autopsy findings from a specialist centre. J Matern Fetal Neonatal Med 2009; 22: 398-404. doi: $10.1080 / 14767050802406677$

37. Adams SM, Good MW, Defranco GM. Sudden infant death syndrome. Am Fam Physician 2009; 79: 870-874.

38. Saul JP, Schwartz PJ, Ackerman MJ, Triedman JK. Rationale and objectives for ECG screening in infancy. Heart Rhythm 2014; 11: 2316-2321. doi: 10. 1016/j.hrthm.2014.09.047

39. Arnestad M, Crotti L, Rognum TO, et al. Prevalence of long-QT syndrome gene variants in sudden infant death syndrome. Circulation 2007; 115:361367. doi: 10.1161/CIRCULATIONAHA.106.658021

40. Son MJ, Kim MK, Yang KM, Choi BH, Lee BW, Yoo SH. Retrospective genetic analysis of 200 cases of sudden infant death syndrome and its relationship with long QT syndrome in Korea. J Korean Med Sci 2018; 33: e200. doi: 10.3346/jkms.2018.33.e200

41. Maron BJ, Doerer JJ, Haas TS, Tierney DM, Mueller FO. Sudden deaths in young competitive athletes: analysis of 1866 deaths in the United States, 1980-2006. Circulation 2009; 119: 1085-1092.

42. Allan KS, Morrison LJ, Pinter A, Tu JV, Dorian P; on behalf of the Rescue Investigators. Unexpected high prevalence of cardiovascular disease risk factors and psychiatric disease among young people with sudden cardiac arrest. J Am Heart Assoc 2019; 8: e010330. doi: 10.1161/jaha.118.010330

43. Mahoney LT, Burns TL, Stanford W, et al. Coronary risk factors measured in childhood and young adult life are associated with coronary artery calcification in young adults: the Muscatine Study. J Am Coll Cardiol 1996; 27: 277-284.

44. Webster G, Olson R, Schoppen ZJ, et al. Cardiac evaluation of children with a family history of sudden death. J Am Coll Cardiol 2019; 74: 759-770. doi: 10.1016/j.jacc.2019.05.062

45. Winkel BG, Risgaard B, Sadjadieh G, Bundgaard H, Haunso S, Tfelt-Hansen J. Sudden cardiac death in children (1-18 years): symptoms and causes of death in a nationwide setting. Eur Heart J 2014; 35: 868-875. doi: 810.1093/eurheartj/eht1509

46. Bagnall RD, Singer ES, Tfelt-Hansen J. Sudden cardiac death in the young. Heart Lung Circ 2020; 29: 498-504. doi: 10.1016/j.hlc.2019.11.007

47. Priori SG, Wilde AA, Horie M, et al. Hrs/ehra/aphrs expert consensus statement on the diagnosis and management of patients with inherited primary arrhythmia syndromes: document endorsed by hrs, ehra, and aphrs in may 2013 and by accf, aha, paces, and aepc in June 2013. Heart Rhythm 2013; 10: 1932-1963.

48. DeWitt ES, Triedman JK, Cecchin F, et al. Time dependence of risks and benefits in pediatric primary prevention implantable cardioverter-defibrillator therapy. Circ Arrhythm Electrophysiol 2014; 7: 1057-1063.

49. Institute of Medicine Committee on the Treatment of Cardiac Arrest. Strategies to Improve Cardiac Arrest Survival: A Time to Act. National Academic Press, Washington, DC, 2015.

50. Blewer AL, Putt ME, Becker LB, et al. Video-only cardiopulmonary resuscitation education for high-risk families before hospital discharge: a multicenter pragmatic trial. Circ Cardiovasc Qual Outcomes 2016; 9: 740-748.

51. Pierick TA, Van Waning N, Patel SS, Atkins DL. Self-instructional CPR training for parents of high risk infants. Resuscitation 2012; 83: 1140-1144.

52. Cummins RO, Ornato JP, Thics WH, Pepe PE. Improving survival from sudden cardiac arrest: the "chain of survival" concept: a statement for health care professionals from the Advanced Cardiac Care Committee, American Heart Association. Circulation 1991; 83: 832-847.

53. Maron BJ. Sudden death in athletes. N Eng J Med 2003; 349: 1064-1075.

54. The American Heart Association in collaboration with the International Liaison Committee on Resuscitation. Part 4: the automated external defibrillator: key link in the chain of survival. In: Guidelines 2000 for cardiopulmonary resuscitation and emergency cardiovascular care. Circulation 2000; 102(Suppl 8): I-60-I-76.

55. Everitt MD, Saarel EV. Use of the wearable external cardiac defibrillator in children. PACE 2010; 33: 742-774. 